\title{
TINGKAT PENGEMBALIAN KREDIT NASABAH UPKD DAN FAKTOR-FAKTOR YANG MEMPENGARUHINYA (Studi di Desa Pagar Agung Kecamatan Seluma Barat Kabupaten Seluma)
}

\author{
Maryono
}

\begin{abstract}
This research aimed to know the rate of return credit from costumers of Pagar Agung UPKD and to know the factors which influence the rate of return credit from the costumer of Pagar Agung UPKD by using primary and secondary data. Data was taken from 35 sample of costumers by using "purposive". The statistic analisis which been used in this research was multiple linier regression by using one tail of $t$-test with confidence level of $95 \%(\alpha=0,05)$ and $f$-test with confidence level $95 \%(\alpha=0,05)$. The result of research showed that the rate of return credit highly varied according to the costumers ability and willingess The result of research by using multiple linier regression showed that on the confidence level of $95 \%$ the long term to be costumers, household income, amount of family respon sibility, education, level of credit were influential significantly, whereas the variable of, age, consumtion and work status were not influential significantly toward the credit rate ot return.
\end{abstract}

Key word: Credit, Rate of Return, Costumers.

\section{PENDAHULUAN}

Tujuan pembangunan nasional Indonesia antara lain adalah untuk meningkatkan kesejahteraan hidup rakyat banyak. Sejak awal pembangunan nasional, upaya mengatasi kemiskinan dan kesenjangan sudah menjadi prioritas program-program pembangunan. Dalam rangka mendukung pengentasan kemiskinan pertumbuhan ekonomi dan mendukung kelestarian lingkungan hidup di Propinsi Bengkulu, pemerintah melaksanakan Bengkulu Regional Development Project (BRDP) yang bekerjasama dengan Bank Dunia (World Bank).

Sejalan dengan tujuan pembangunan untuk meningkatkan kesejahteraan hidup rakyat banyak kendala yang dihadapi, antara lain persediaan modal bagi masyarakat. Dalam rangka membentuk masyarakat dalam menyediakan permodalan dalam berusaha, pemerintah telah membuka kesempatan melalui berbagai kegiatan perbankan, yaitu dalam bentuk kredit. Hal ini juga dilaksanakan oleh Bengkulu Regional Development Project 
(BRDP) yang bekerjasama dengan Bank Dunia (World Bank), yang salah satu kegiatannya adalah menyalurkan kredit bagi masyarakat (Farial, dkk., 1997).

Bengkulu Regional Development (BRDP) yang berada di 370 Desa, didalam 8 Kabupaten yang dibagi menjadi lima tahap. Dimana kegiatan yang dilakukan antar lain: dana usaha ekonomi produktif dalam bentuk dana bergulir. Dimana dana bergulir ini nantinya akan disalurkan kepada masyarakat desa dengan melalui kredit untuk sebagai modal usahanya. Untuk memperlancar kegiatan tersebut maka disetiap desa dibentuklah unit pengelolah keuangan desa (UPKD) (Laporan akhir BRDP, 2002-2005).

Kabupaten Seluma merupakan salah satu Kabupaten dari delapan yang mendapatkan proyek tersebut. Sampai tahun 2005 pelaksanaan sudah mencapai lima tahapan, dalam arti kata terjadinya penambahan jumlah desa. Untuk melihat tingkat keberhasilan dana bergulir ini yang melalui UPKD dapat dilihat pada tingkat pengembalian kredit yang terjadi setiap bulannya.

Program BRDP berhenti bulan Agustus 2005, sehingga dana yang digulirkan kepada masyarakat dalam bentuk kredit akan dijalankan oleh pengurus UPKD yang sudah dipilih sebelumnya. Penyaluran kredit UPKD kepada nasabah bertujuan membantu modal didalam melakukan kegiatan seperti bertani, berdagang dan usaha-usaha produktif lainnya.

Tingkat pengembalian pinjaman oleh nasabah akan sangat menentukan berhasil atau tidaknya suatu UPKD dan merupakan sebagai pertimbangan bagi pengurus UPKD di dalam melakukan pinjaman untuk selanjutnya. Adapun maksud dari penelitian ini adalah untuk mengetahui tingkat pengembalian kredit nasabah pada UPKD di desa Pagar Agung Kecamatan Seluma Barat Kabupaten Seluma, dan faktor-faktor yang mempengaruhi tingkat pengembalian kredit 


\section{METODE PENELITIAN}

Penentuan daerah penelitian dilakukan dengan secara sengaja (Purposive) yaitu di desa Pagar Agung Kecamatan Seluma Barat Kabupaten Seluma. Desa Pagar Agung yang berjumlahkan $160 \mathrm{KK}$, pemilihan lokasi ini dilakukan atas pertimbangan bahwa masyarakat yang ada di desa Pagar Agung hampir semuanya menjadi anggota UPKD. Adapun responden dalam penelitian ini adalah nasabah UPKD Karya Agung. Populasi sebanyak 116 orang dengan kriteria periode peminjaman 1 Juli 2005 sampai dengan 30 Juni 2006. sampel yang diambil $30 \%$ sehingga diperoleh sampel sebanyak 35 orang. Sampel diambil dengan metode "puposive” (sengaja).

Analisa data yang digunakan untuk mengetahui tingkat pengembalian kredit menggunakan rumus berikut:

Tingkat pengembalian $(\%)=\frac{\text { Jumlah angsuran sampai bulan terakhir }}{\text { Jumlah target angsuran bulan terakhir }} \quad$ X $100 \%$

Untuk menentukan pengaruh variabel bebas (independent variabel) terhadap variabel tidak bebas (dependent variabel) digunakan model regresi linier berganda. Variabel bebas (Xi) yang digunakan yaitu total pendapatan, jumlah tanggungan keluarga, umur, pendidikan, besarnya kredit dan satu variabel dummy yaitu status pekerjaan, sedangkan variabel tidak bebas (Y) yang digunakan adalah tingkat pengembalian kredit.

Secara matematis metode tersebut dapat ditulis sebagai berikut:

$Y=b o+b_{1} X_{1}+b_{2} X_{2}+b_{3} X_{3}+b_{4} X_{4}+b_{5} X_{5}+b_{6} D+e$

Dimana:

$$
\begin{array}{ll}
\mathrm{Y} & =\text { Persentase pengembalian (variable terkait) (\%) } \\
\mathrm{X}_{1} & =\text { Total pendapatan (Rp/bulan) } \\
\mathrm{X}_{2} & =\text { Jumlah tanggungan keluarga (jiwa) } \\
\mathrm{X}_{3} & =\text { Pendidikan (tahun) } \\
\mathrm{X}_{4} & =\text { Umur (tahun) } \\
\mathrm{X}_{5} & =\text { Besarnya kredit (Rp) }
\end{array}
$$


D = Variabel Dummy, yakni (1 jika status pekerjaan petani dan 0 jika status pekerjaan non petani).

bo $=$ Konstanta regresi

$\mathrm{b}_{1}-\mathrm{b}_{5}=$ Koefisien regresi

$\mathrm{e} \quad=$ Kesalahan pengganggu

1. Untuk pengujian hipotesis secara bersama-sama dengan menggunakan uji $\mathrm{F}$, dan untuk pengujian hipotesis terhadap masing-masing variabel bebas mengunakan uji $\mathrm{T}$,

\section{HASIL DAN PEMBAHASAN}

\subsection{Tingkat Pengembalian Kredit Periode 1 Juli 2005 s/d 30 Juni 2006}

Tabel 1. Tingkat Pengembalian Kredit responden UPKD Karya Agung.

\begin{tabular}{lcccc}
\hline \multicolumn{2}{c}{ Tingkat pengembalian } & $\begin{array}{r}\text { Jumlah } \\
\text { (jiwa) }\end{array}$ & $\begin{array}{c}\text { Persentase } \\
(\%)\end{array}$ & $\begin{array}{c}\text { Rata-rata persentase } \\
\text { pengembalian }(\%)\end{array}$ \\
\hline Tinggi & $(\geq 104)$ & 3 & 8,57 & 71 \\
Sedang & $(35-104)$ & 22 & 62,86 & \\
Rendah $\quad(\leq 35)$ & 10 & 28,57 & \\
\hline \multicolumn{2}{c}{ Jumlah } & 35 & 100 & \\
\hline
\end{tabular}

Sumber : Data Primer diolah, 2006

Berdasarkan hasil penelitian tingkat pengembalian kredit nasabah UPKD Karya Agung dari 1 Juli 2005 sampai dengan 30 Juni 2006 sangat bervariasi. Ada nasabah yang belum mengembalikan kreditnya ( 0 persen) dan ada yang mengembalikan kredit sebesar 276 persen. Nasabah menyatakan bahwa sanksi dari pihak UPKD tidak begitu memberatkan jika terlambat dalam pengembalian kredit. Hal ini tercermin dari pihak UPKD yang tidak langsung memberikan sanksi kepada nasabah sesuai dengan isi perjanjian yang ada

Pengembalian kredit nasabah ada yang melewati dari 100 persen. Hal ini disebabkan karena adanya interval antara tanggal mulai pinjam dengan data yang diambil hanya berjarak 5 bulan, sehingga dari perhitungan ini menghasilkan tingkat pengembalian kredit mencapai 276 persen atau melebihi 100 persen. Dari rata-rata tingkat pengembalian kredit yang ada maka pengembalian kredit tergolong sedang yang dilihat dari rata-rata sebesar 71 persen. 


\section{Analisis Regresi Faktor-Faktor yang Mempengaruhi Tingkat Pengembalian Kredit}

Pendugaan pengaruh faktor-faktor yang mempengaruhi tingkat pengembalian kredit pada penelitian ini menggunakan fungsi Regresi Linier Berganda. Hasil analisis pendugaan fungsi pengembalian disajikan pada Tabel 2 berikut :

Tabel 2. Hasil Estimasi Faktor-faktor yang Mempengaruhi Tingkat Pengembalian kredit

\begin{tabular}{lccc}
\hline \multicolumn{1}{c}{\begin{tabular}{c} 
Variabel bebas \\
\multicolumn{1}{c}{ Xi) }
\end{tabular}} & $\begin{array}{c}\text { Koefisien Regresi } \\
(\mathrm{bi})\end{array}$ & $\begin{array}{c}\text { Standar } \\
\text { Error }\end{array}$ & t-hitung \\
\hline Pendapatan (X1) & $4,251 \mathrm{E}-05$ & 0,000 & $2,145^{*}$ \\
Jumlah tanggungan keluarga (X2) & $-23,241$ & 8,869 & $-2,621^{*}$ \\
Pendidikan (X3) & 5,981 & 2,802 & $2,134^{*}$ \\
Umur (X4) & $-0,346$ & 1,094 & $-0,316$ \\
Besarnya kredit (X5) & $-1,872 \mathrm{E}-05$ & 0,000 & $-2,097^{*}$ \\
Konsumsi (X6) & $-6,257 \mathrm{E}-05$ & 0,000 & $-1,341$ \\
Status pekerjaan (D) & 4,115 & 19,878 & 0,207 \\
\hline
\end{tabular}

Sumber : Data Primer diolah, 2006

Keterangan $\quad: *$ Berpengaruh nyata pada tingkat kepercayaan $95 \%$

Konstanta $\quad: 148,132$

$\mathrm{R}^{2}: 0,572$

$\mathrm{t}(0,05)(27) \quad: \pm 1,703$

$\mathrm{F}(0,05)(7)(27) \quad: 2,386$

Dari Tabel 2 di atas dapat dilihat bahwa nilai determinasi $\left(\mathrm{R}^{2}\right)$ sebesar 0,572 yang berarti ke tujuh variabel bebas yaitu : pendapatan, jumlah tanggungan, pendidikan, umur, besarnya kredit, konsumsi dan status pekerjaan mampu menjelaskan hanya 57 persen keragaman dari variabel tak bebas (Y) dan sisanya sebesar 43 persen dipengaruhi oleh faktor-faktor lain yang tidak diidentifikasi dalam model.

Hasil uji F menunjukkan bahwa pada taraf kepercayaan 95\% $(\alpha=0,05)$ Fhitung lebih besar dari Ftabel $(5,147>2,386)$ sehingga Ho ditolak dan Hi diterima artinya secara bersama-sama variabel bebas yakni faktor pendapatan (X1), jumlah tanggungan (X2), pendidikan (X3), umur (X4), besarnya kredit (X5), konsumsi (X6) dan status pekerjaan (D) berpengaruh nyata terhadap pengembalian kredit (Y). 
Nilai uji t dari masing-masing faktor dalam model menunjukkan bahwa variabel pendapatan, jumlah tanggungan, pendidikan dan besarnya kredit berpengaruh nyata terhadap tingkat pengembalian kredit, sedangkan variabel lainnya (umur, konsumsi dan status pekerjaan) tidak berpengaruh nyata terhadap pengembalian kredit. Pengaruh dari masing-masing variabel bebas terhadap variabel tidak bebas, secara berturut-turut diuraikan sebagai berikut :

\section{a. Pengaruh Pendapatan (X1) Terhadap Tingkat Pengembalian Kredit (Y)}

Dari hasil analisis regresi yang tertera pada Tabel 2 diketahui bahwa jika pendapatan meningkat maka pengembalian juga akan meningkat. Dengan kata lain, naiknya pendapatan memungkinkan nasabah mengangsur kreditnya sesuai dengan jangka waktu yang telah ditentukan dan sebaliknya jika pendapatan nasabah menurun maka pengembalian pun akan menurun dan kemungkinan nasabah didalam mengembalikan kredit juga akan tertunda.

Pendapatan rumah tangga nasabah UPKD Karya Agung sebagian besar dari sektor pertanian. Dengan pendapatan yang tinggi sangat memungkinkan nasabah UPKD dapat membayar kredit lebih cepat serta dengan besarnya pendapatan mampu meningkatkan kesejahteraan nasabah. Hal ini sejalan dengan penelitian sebelumnya yang dilakukan oleh Herawaty (2006), yang menyatakan bahwa besarnya pendapatan petani ikan mas berpengaruh nyata terhadap tingkat pengembalian kredit, karena besarnya pendapatan petani ikan mas memberikan motivasi dalam meningkatkan hasil produksi sehingga dapat membayar uang yang dipinjam beserta bunga yang dibebankan. Hal ini sejalan juga dengan penelitian yang dilakukan oleh Farial, dkk (1997), yang menyatakan bahwa besarnya pendapatan usahatani kelapa hibrida berpengaruh nyata terhadap kelancaran pengembalian kredit, dimana dengan semakin besar penghasilan yang diperoleh maka kemampuan untuk mengembalikan kredit semakin besar. 


\section{b. Pengaruh Jumlah Tanggungan (X2) Terhadap Tingkat Pengembalian (Y)}

Hasil analisis yang disajikan pada Tabel 2 diketahui bahwa semakin banyak jumlah tanggungan keluarga maka pengambalian kredit juga akan semakin menurun dan sebaliknya semakin sedikit jumlah tanggungan keluarga maka semakin tinggi pengembalian kredit nasabah. Hasil ini sejalan dengan hasil penelitian Farial, dkk (1997) yang menyatakan bahwa jumlah tanggungan berpengaruh nyata terhadap pengembalian kredit karena semakin banyak jumlah tanggungan keluarga akan menyebabkan pengembalian kredit menjadi semakin rendah.

\section{c. Pengaruh Pendidikan (X3) Terhadap Tingkat Pengembalian (Y)}

Dari Tabel 2 diketahui pendidikan yang tinggi maka pengembalian kredit juga akan semaki tinggi dan sebaliknya jika pendidikannya semakin rendah kemungkinan nasabah untuk mengembalikan kredit juga akan semakin kecil (rendah), dengan kata lain tingginya pendidikan seorang nasabah akan menjamin pengembalian kreditnya juga akan tinggi. Penelitian sesuai dengan penelitian Farial, dkk, (1997) yang menyatakan bahwa pendidikan berpengaruh nyata secara positif terhadap kelancaran pengembalian kredit usahatani kelapa hibrida.

\section{d. Pengaruh Umur (X4) Terhadap Tingkat Pengembalian (Y)}

Dari Tabel 2 diketahui bahwa jika semakin muda umur nasabah maka pengembalian kredit akan semakin tinggi dan sebaliknya jika umur nasabah semakin tua maka pengembalian kreditnya akan semakin kecil. Hal ini cukup beralasan karena nasabah yang berumur muda pada umumnya mempunyai kesamaan bekerja keras dalam berusaha agar mendapatkan pendapatan yang lebih tinggi untuk memenuhi kebutuhan sehari-hari dan membayar kredit. Hal ini sejalan dengan penelitian sebelumnya yang dilakukan oleh Riniwati, dkk (1997) yang menyatakan bahwa umur berpengaruh nyata terhadap pengembalian kredit. Ia mengemukakan bahwa semakin muda semakin respon terhadap 
kredit dan semakin tua semakin tidak respon. Karena nelayan yang berumur muda pada umumnya lebih respon terhadap teknologi, sehingga permodalan dan biaya operasi yang dibutuhkan lebih tinggi.

\section{e. Pengaruh Besarnya kredit (X5) dengan Pengembalian Kredit (Y)}

Hasil analisis regresi yang disajikan pada Tabel 2 diketahui bahwa semakin besar jumlah pinjaman nasabah maka pengembalian kreditnya akan semakin kecil dan begitu juga sebaliknya hal ini disebabkan karena dengan pinjaman yang besar maka angsuran setiap bulannya juga akan semakin besar begitu juga dengan bunga yang ditanggung oleh nasabah. Hal ini disebabkan besarnya kredit yang dipinjam oleh nasabah terkadang tidak semuanya digunakan untuk usaha bahkan terkadang sama sekali tidak dipergunakan sebagai modal usaha. Dimana uang yang dipinjam terkadang hanya digunakan untuk keperluan konsumsi keluarga.

\section{f. Pengaruh Konsumsi (X6) Terhadap Pengembalian Kredit (Y)}

Hasil analisis regresi yang disajikan pada Tabel 2 diketahui bahwa jika tingkat konsumsi keluarga meningkat maka pengembalian kredit akan semakin kecil karena nasabah akan cenderung untuk memenuhi atau mendahulukan kebutuhan keluarganya. Dari hasil penelitian menunjukkan bahwa konsumsi rumah tangga nasabah yang terbesar adalah pemenuhan pangan dan biaya pendidikan anak-anak mereka, sehingga akan mengakibatkan keterlambatan membayar kredit. Dengan demikian besar kecilnya tingkat konsumsi tidak serta merta berpengaruh terhadap tingkat pengembalian kredit. Hal ini sejalan dengan penelitian Herawaty (2006) ia menyatakan bahwa bahwa konsumsi rumah tangga petani ikan mas berpengaruh tidak nyata terhadap tingkat pengembalian kredit.

\section{g. Pengaruh Status Pekerjaan (D) Terhadap Pengembalian Kredit (Y)}


Tabel 2 menunjukkan bahwa ada perbedaan di dalam pengembalian kredit antara nasabah yang status pekerjaannya sebagai petani dan nasabah yang status pekerjaannya non petani. Dengan demikian bahwa status pekerjaan nasabah tidak menjamin cepat atau lambatnya pengembalian kredit, tingkat pengembalian kredit kemungkinan $h$ ditentukan oleh motivasi pengembalian nasabah dari pada status pekerjaan nasabah

\section{KESIMPULAN DAN SARAN}

\section{Kesimpulan}

Berdasarkan hasil penelitian dan pembahasan yang telah dilakukan, maka dapat ditarik kesimpulan sebagai berikut : Tingkat pengembalian kredit nasabah UPKD Karya Agung di desa Pagar Agung bervariasi yaitu 0 persen sampai 276 persen dengan rata-rata pengembalian kredit sebesar 71 persen. Dan variabel bebas yang diteliti yang berpengaruh nyata pada taraf kepercayaan $95 \%$ terhadap tingkat pengembalian kredit yaitu pendapatan, jumlah tanggungan keluarga, pendidikan, dan besarnya kredit. Sementara itu, variabel bebas lainnya, umur, konsumsi, dan status pekerjaan tidak berpengaruh nyata terhadap tingkat pengembalian kredit

\section{Saran}

Diharapkan variabel pendapatan rumah tangga, jumlah tanggungan keluarga, pendidikan dan besarnya kredit calon nasabah menjadi pertimbangan bagi pihak UPKD saat penyeleksian permohonan pinjaman kredit mengingat kelancaran pengembalian kredit. Selain itu hendaknya juga UPKD melakukan evaluasi terhadap tingkat pengemb kredit secara konsisten dan memberikan sanksi terhadap nasabah yang sengaja meng $r$ ulur waktu pengembalian kreditnya.

\section{DAFTAR PUSTAKA}

Anonim. 2006. Laporan Keuangan dan Data Statistik UPKD. Desa Pagar Agung 
BRDP. 2005. Laporan Akhir Tahun 2002-2005 Program Kegiatan Desa. Unit Pengelola Keuangan Desa (UPKD) Propinsi Bengkulu. Bina Swadaya. Bengkulu.

Farial, H,. A.I. Hasyim dan M. Irfan A. 1997. Analisis Fakor-faktor yang Mempengaruhi Kelancaran Pengembalian Kredit Investasi Usahatani Kelapa Hibrida pada Proyek TCSDP (Tree Crop Smallholder Development Project) Provinsi Lampung. JPP 9(8) Fakultas Pertanian Universitas Lampung. Lampung

Herawaty, Tetty. 2006. Analisis Determinan Tingkat Pengembalian Kredit Umum Pedesaan oleh Petani Ikan Mas pada BRI Unit Porsea. Skripsi, Fakultas Pertanian UNIB, Bengkulu (tidak dipublikasikan)

Nazir. 1988. Metode Penelitian. Ghalia Indonesia, Jakarta.

Nurdin, Harto.1981. Dasar-dasar Demografi. Lembaga Penerbit FEUI. Jakarta.

Riniwati H, N. Harahap, dan P. Purwanti. 1997. Evaluasi Kredit Informal Terhadap Usaha Penangkapan Ikan dan Konsumsi Rumah Tangga Nelayan Dalam Upaya Memperbaiki Sistim Perkreditan di Desa Pantai Pasuruan, Jawa Timur. JPSS 9(2) : 57-68. Fakultas Perikanan Universitas Brawijaya

Rozin, Hendri. 2004. Faktor-Faktor yang Berhubungan dengan Partisipasi Masyarakat Peserta Proyek Unit Pelayanan Pengembangan Pengolahan Hasil Pertanian (UP3HP) di Kota Bengkulu. Skripsi FP UNIB, Bengkulu (tidak dipublikasikan)

Sujono, Hasan. 1993. Dinamika Kependudukan di Indonesia. PT. Rineka Cipta. Jakarta. 